\title{
Core Values for Language Lab Directors and Lab Attendants
}

\author{
Patricia Lamb \\ University of California-Santa Barbara
}

\section{Introduction}

"Values play a significant role in shaping the life of both the individual and the community."

-Dr. Alexie Crane, Unitarian Universalist Minister

Core Values
During the 1996/97 academic year, I had the unfortunate experience of telling four of my sixteen lab attendants they no longer had jobs in the learning lab. I had made great efforts to work with these people, giving them the benefit of the doubt several times. Eventually Irealized, with great disappointment, that they were not going to be able to meet my standards of appropriate behavior on the job, and I let them go. If you have ever been through this experience, you know how terrible it feels. The most disturbing part about that particular year was the realization that I had gone through this process in one year with more employees than in the previous 10 years combined! Ibegan to do some deep soul searching and examination of my own supervisory style. I came to the conclusion that I could no longer assume my lab attendants knew what I considered to be basic expectations and standards. I needed to make my expectations more explicit. In the "Staff Development" module of The IALL Management Manual, my colleague LeeAnn Stone (University of California-Irvine)) and I provide ideas and methods for managing staff, but we don't directly address the underlying values which are the foundation of a successful management style. In partnership with LeeAnn, I developed the following list of core values along with a discussion on how to incorporate these values into the culture of our labs.

During the Lab Management Workshop at FLEAT III, many values were added to our core list by workshop participants. Your own list would have to include specific values which would support the atmosphere you are trying to achieve in your lab. The following list reflects my own 
"I appreciate it when a new employee gives a fresh perspective on the way we do things and questions policies or procedures that don't seem quite to fit the situation anymore." personal top priorities for qualities in a good employee, but it certainly is not all inclusive:

1. Positive attitude. I want to work with people who take the job seriously and who enjoy being there. No grumps, please. I consider working in the labs to be one of the most interesting jobs on campus. It's an opportunity to learn about technology and people, with room for a considerable amount of personal growth.

2. Consistency, dependability, reliability, self-motivation. I want to know, with a high degree of certainty everyday, that my fellow workers are going to show up and on time. And once they get here, I want to feel confident that they will know what the priorities are and follow through by doing their job.

3. Initiative. Have you ever had a lab attendant who noticed that the old form you were still using was obsolete? I appreciate it when a new employee gives a fresh perspective on the way we do things and questions policies or procedures that don'tseem quite to fit the situation anymore. Even more exciting is when they take it one step further and suggest a new solution to a given process in the operation of the lab.

4. Spirit of cooperation. I want all my lab attendants, depending on their experience and expertise, to share the responsibility of the lab equally. No one should take advantage of the others by not carrying their share of the load. Typically, students work short, 2- to 4-hour shifts. Teamwork in the labs involves successfully passing the ball to the person coming on duty.

5. Sense of responsibility and honesty. How many of us provide our lab attendants with the keys to the lab? This act alone requires a high degree of trust. How many of us are in the labs actively supervising our lab attendants at all times? If your lab is open more than 40 hours per week, your lab attendants may be working without an on-site supervisor for part of the week. A self-motivated staff, responsible for accomplishing the goals and providing the services, is required under those circumstances.

6. Good communication skills. Lab attendants answer the phone, interact with faculty, staff and students. They may also be required to write messages, lists, instructions, explanations, etc. Being articulate, concise, polite and courteous are vital communication skills in the busy lab environment. I realize that this is more of a skill than a value, but I am compelled to include it in this list anyway! Given the nature of our business, how could I not? 
7. Flexibility. I know that my lab attendants' top priority is going to school. But after school, I want the job to rank as a high priority in their lives. I go to great lengths to plan their work schedule around their class schedule and I appreciate their willingness to work an occasional weekend, early morning or late night.

8. Analytical skill. Learning labs are complex places. We provide a wide variety of services for a diverse clientele. When our lab attendants can see the whole process from $A$ to $\mathrm{Z}$ and think about what impact a decision they make might have on another aspect or function of our business, that is a valuable employee indeed!

Promoting Core Values

Hiring
The campaign to promote the desired values into the culture of your lab can be incorporated into all areas of lab management, beginning with the hiring process and continuing with training and supervision. If we make our expectations known from the very beginning, and follow through with lots of reinforcement every step of the way, our chances for successfully creating "The Dream Team" will be much enhanced.

The first contact a prospective employee has with you, and therefore with your expectations, may be through your application for employment. A few years ago, I wrote an article for The Journal about a cooperative recruitment effort (Volume 27, Number 2, Spring 1994). Part of this effort involved the development of an application which would contain information and ask questions purposely designed to give the desired impression that employees in this department must be competent professionals.

We started by writing a mission statement and printed it at the top of the second side of the application:

Classroom Services is the arm of Instructional Development that meets the needs of professors, students and staff in all delivery and display capacities. We are the front line point of contact for technical support in the classroom, lecture halls and special events. Our charge is to provide "no miss" service: to be on time, reliable, courteous under duress and technically competent.

Following the mission statement is a five part question with plenty of room for the applicant to write an answer to each part: What experiences have you had which display your strengths in the areas of: 1 . self-motivation, 2. punctuality, 3. reliability, 4. attention to detail, and 5. dealing with a 
variety of people and situations.

The mission statement and the questions begin to give the applicant an idea of what we expect of ourselves, and of anyone who works with us. The answers to the questions make for some very interesting reading. Some people put time and care into their answers, others don't. If you have a lot of applicants for your lab attendant positions, your initial stage of weeding out can be to eliminate those who don't take the application seriously by answering thoughtfully.

When you interview prospective lab attendants, you have a great opportunity to ask questions related to the values that are important to you and to discuss with the applicant why these particular values are important in this job. Do you have any trouble being on time? If needed, are you available to work weekends or evenings? In previous jobs, have you ever been given the keys to the place where you worked? Have you had any experience working on several projects at once? How do you feel about interruptions? Can you be self-motivated in an indirectly supervised or unsupervised atmosphere? How do you prefer to be supervised? How would you handle the following situation: you are at work, and there is no apparent work to be done? Would you enjoy a job which requires serving clients? Do you prefer working with a team of employees or on your own? Would you enjoy working in a busy atmosphere? What would you do in the following situation: you are working at the front desk, two students walk up to the desk, a professor walks up to the desk, and the phone rings, all at once? What qualities do you have that would make you a good lab attendant? This line of questioning adds substance to the standard "What did you do in your past employment, and what hours can you work?" You will spend a half hour or so getting to know the applicant and, just as importantly, giving them the opportunity to learn more about the kind of commitment they may be making by accepting the job!

\section{Training}

Quite a bit of information on training is included in the "Staff Development" module of The IALL Management Manual, and I am not going to repeat that here, except to illustrate some ideas for emphasizing values during the training process. When the training sessions begin, shortly after I welcome my new staff to their new job, we go over a list of "Lab Etiquette" do's and don'ts. This list, which could just as easily be called "Patty's Pet Peeves," is included in a handbook which the new lab attendants receive when they are hired and have already had an opportunity to read before the training begins. 
The items on the list all relate to professionalism and values important to the work place. Some of the items may seem obvious and hardly necessary to mention, but they are all on the list as a result of past experience with lab attendants. Therefore, to avoid possible misunderstandings, we discuss issues such as: why it isn't a good idea to put one's feet up and read the newspaper at the front desk; why one should not leave the labs until another lab attendant arrives for his or her shift; why the phone is not available for personal use; why we are required to wear shoes to work (remember, this is California); when it is appropriate to study while on duty; where a snack may discreetly be consumed, etc. Do any of these ring a bell with you as a reader?

Including your returning lab attendants in the training process as trainers can support your desire for cooperation and teamwork. A mature, experienced lab attendant can help you promote a positive and professional attitude. This fall we did lots of role playing with trainers pretending to be lab clients and trainees acting as lab attendants. Role playing allows you, in a humorous way, to exaggerate problems, feelings and reactions. It loosens everyone up and breaks the ice but at the same time gives concrete examples of both the services the trainees have been learning about and appropriate (or, even more fun, inappropriate) ways to interact with our clients.

New lab attendants have often expressed feeling overwhelmed by all the information they are given during training. I try to alleviate their anxiety and simplify the expectations by giving them a short list of their priorities on the job. This list relates directly to the value of self-motivation, in that it helps the lab attendants to think about what I expect them to pay attention to when they are on duty. The number one item on the list is "helping lab clients." Next on the list are "production" (audio cassettehigh speed duplication), "special assignments" (primarily areas of the lab or record keeping they are responsible for), and "cleanliness and orderliness of the lab environment." This four item list not only helps the lab attendants prioritize their work, but also serves as a reminder that in our work place, people come first.

Supervising I strive to give my lab attendants lots of room to develop and use the values I am promoting by allowing them to work as independently as possible. I also encourage and support creative solutions to problems which arise from time to time in our constantly changing technological environment. Tom Morris, a former philosophy professor turned corporate 
consultant and the author of "If Aristotle Ran General Motors" was asked, "If a philosophy professor can consult to Fortune 500 companies, can a philosophy major now at least get a job?" He replied, "At their best, philosophy majors can be very powerful, creative employees. But in a command-and-control organization - the model that, for better or worse, most companies still follow - who wants a creative employee?" I do! And I am so glad I work in a university environment where creativity is allowed and encouraged.

There is a flip side to the coin, however. The down side to allowing lab attendants to work independently is that I sometimes discover that a particular employee needs more guidance than they may be getting from me in order to be successful in the job. They may have many positive qualities which fit in nicely with the core values, but may still be developing in the area of, for example, self motivation. I can always fall back on the four priorities mentioned above to help this lab attendant become a more independent worker. I have found it to be important to recognize and act when I observe that an employee is not moving toward developing the desired values because, if I ignore the situation and pretend it will go away or improve on its own, it just gets worse.

In speaking to other supervisors of student employees on her campus, LeeAnn Stone discovered that there was a double standard of expectations. Some supervisors didn't expect students to behave or perform on the job as professionally as they would a non-studentstaffemployee. The attitude was that we couldn't expect students to take the job seriously and had to tolerate lower levels of performance. I think we do both students and ourselves a disservice by this attitude. Students who do take the job seriously have the opportunity to make tremendous gains in both their professional and personal lives. As LeeAnn emphasized during the FLEAT III workshop, "We in fact do these students a disservice by not supervising them in the same way and with the same expectations that we would any other employee."

Patricia (Patty) Lamb is Labs Manager for Instructional Resources in the Language \& Learning Labs, University of California-Santa Barbara. She is also the Secretary/ Parliamentarian of IALL. 